\title{
Analisis getaran dan kebisingan pada kamar mesin dan geladak penumpang kapal cepat Aluminium
}

\author{
Amalia Ika Wulandari ${ }^{*}$, Suardi ${ }^{2}$, Muhammad Yusuf Ismail ${ }^{3}$ \\ 1,2,3Teknik Perkapalan, Jurusan Sains Teknologi Pangan dan Kemaritiman, Institut Teknologi \\ Kalimantan \\ Karang Joang, Balikpapan, Kalimantan Timur, Indonesia \\ ${ }^{*}$ Corresponding author: amaliaikaw@lecturer.itk.ac.id
}

\begin{abstract}
Ship vibration is part of the problem with ship dynamics. In addition to producing noise that disturbs the comfort of crew and passengers, engine structures and components can be damaged due to vibrations that are too high, resulting in material fatigue and material deformation. In order to avoid the damage that occurs and in order to improve the comfort of passengers and crew, shipbuilding must comply with vibration and noise standards. This study aims to analyze the value of vibration and the value of noise that arises on the aluminum fast boat as a result of excitation in terms of the main engine. Calculation of natural frequency and mode shapes is done using ship modeling with Finite Element Analysis Software. The excitation frequency of the main engine is $35.014 \mathrm{~Hz}$. Based on the system's amplitude calculation, the values range from $3.273 \times 10-7$ to $2.703 \times 10-6$. Then the vibration standard values obtained are in the range of values from 0.253 to 2.093. Then, the noise radiation value obtained is in the range of 134,582 $d B$ to $130,449 \mathrm{~dB}$. All research results regarding vibration and noise standards in the engine room and passenger deck of aluminum ships obtained results that meet the standards, so it can be concluded that the ship's construction is safe from excessive vibration and noise.
\end{abstract}

Keyword: Natural frequency, Finite Element Method, high speed vessel.

\begin{abstract}
Abstrak
Getaran kapal adalah bagian dari masalah pada dinamika kapal. Selain menghasilkan kebisingan yang menggangu kenyamanan para awak dan penumpang, struktur dan komponen mesin dapat rusak akibat getaran yang terlalu tinggi sehingga mengakibatkan kelelahan material dan perubahan bentuk material. Untuk menghindari kerusakan yang terjadi dan agar dapat meningkatkan kenyaman penumpang serta awak kapal, pembuatan kapal harus memenuhi standar getaran dan kebisingan. Penelitian ini bertujuan untuk menganalisis nilai getaran serta nilai kebisingan yang timbul pada kapal cepat aluminium akibat dari eksitasi yang ditinjau dari mesin induk. Perhitungan frekuensi natural dan mode shapes dilakukan menggunakan permodelan kapal dengan Program Analisis Elemen Hingga. Frekuensi eksitasi dari mesin induk adalah $35.014 \mathrm{~Hz}$. Berdasarkan perhitungan amplitudo sistem yang didapatkan rentang nilai 3.273 x 10-7 hingga $2.703 \times 10-6$. Kemudian nilai standar getaran yang didapatkan berada di rentang nilai 0.253 hingga 2.093. Selanjutnya nilai radiasi kebisingan yang didapatkan berada di rentang nilai $134.582 \mathrm{~dB}$ hingga $130.449 \mathrm{~dB}$. Seluruh hasil penelitian mengenai standar getaran dan kebisingan pada kamar mesin dan geladak penumpang kapal aluminium mendapatkan hasil yang memenuhi standar, sehingga dapat disimpulkan konstruksi kapal tersebut aman dari getaran dan kebisingan yang berlebih.
\end{abstract}

Kata kunci: Frekuensi natural, Metode Elemen Hingga, kapal cepat.

\section{Pendahuluan}

Aluminium cukup banyak digunakan sebagai material untuk membuat kapal cepat. Hal ini di lakukan karena aluminium memiliki massa yang lebih ringan daripada baja sehingga cocok untuk 
kapal yang membutuhkan kecepatan tinggi. Material aluminium juga banyak dipilih karena dinilai lebih tahan terhadap korosi dibanding dengan material baja [1]

Kekuatan struktur material dari kapal aluminium memiliki perbedaan dengan kapal material baja atau yang menggunakan material lainnya. Kapal aluminium juga memiliki perbedaan kekuatan terhadap getaran dibandingkan dengan kapal dengan material lain. Kekuatan struktur Aluminium tidak lebih baik dibandingkan baja karbon, sehingga kurang baik dalam menahan getaran pada kapal [2].

Getaran kapal adalah bagian dari masalah pada dinamika kapal. Selain menghasilkan kebisingan yang menggangu kenyamanan para awak dan penumpang, struktur dan komponen mesin dapat rusak akibat getaran yang terlalu tinggi sehingga mengakibatkan kelelahan material dan perubahan bentuk material serta terjadinya keausan sehingga kejadian tersebut merupakan penyebab dari meningkatnya celah pada bagian - bagian yang rapat sehingga menyebabkan keretakan pada struktur kapal [3].

Umumnya, getaran pada kapal bersumber dari adanya gaya internal pada sistem propulsi kapal, sehingga perlu diperhatikan agar getaran yang dihasilkan oleh sitem propulsi kapal tidak melebihi dari batas yang ditentukan. Untuk menghindari getaran yang terjadi dalam meningkatkan kenyaman penumpang kapal, pembuatan kapal harus memenuhi standar yang berlaku [4][5].

\section{Tinjauan Pustaka}

\section{Sistem propulsi kapal}

Suatu kapal dalam pengoperasiannnya, diharuskan agar memiliki kemampuan dalam mempertahankan kecepatan yang telah di rancang. Oleh karena itu, perlunya dimiliki rancangan sistem penggerak kapal (propeller, mesin, dll) yang mampu untuk mengatasi seluruh gaya hambat (total resistance) pada lambung kapal agar kapal tersebut dapat memenuhi standar kecepatan rancangannya [6].

Ada tiga komponen utama Sistem Propulsi Kapal diantaranya, yaitu: (a) Motor Penggerak Utama (main engine); (b) Sistem Transmisi (gear box); dan (c) Alat Gerak (propulsor). Tiga komponen utama tersebut adalah suatu kesatuan komponen kapal yang tidak dapat ditinjau secara terpisah dalam proses perencanaannya [7].

Sistem poros dalam sistem penggerak kapal memiliki fungsi sebagai sistem transmisi putaran dan daya yang bersumber dari mesin induk menuju ke propeller untuk menggerakan kapal pada kecepatan tertentu [8].

\section{Getaran}

Getaran pada kapal merupakan suatu fenomena yang timbul akibat adanya transfer gaya pada elemen mesin, sehingga elemen tersebut saling bereaksi satu sama lain melalui struktur dan bergetar. Keausan dan kerusakan serta perubahan bentuk akan merubah karakteristik dinamis sistem yang cenderung dapat meningkatkan energi getaran [9].

Getaran bebas dan getaran paksa merupakan 2 kelompok getaran yang secara umum diketahui. Getaran bebas terjadi saat sistem berosilasi karena gaya yang ada dalam sistem itu sendiri (inherent) dan saat tidak ada gaya luar yang mempengaruhi. Sedangkan getaran paksa adalah getaran yang terjadi karena adanya rangsangan gaya luar yang berisolasi dengan sistem sehingga sistem dipaksa untuk bergetar pada frekuensi rangsangan. Apabila eksitasi harmonik paksa memperngaruhi sebuah sistem, maka pada frekuensi yang sama respon getarannya akan berlangsung dengan frekuensi eksitasinya [10]. Getaran paksa biasanya terjadi pada getaran pondasi karena mesin yang bertumpu di atasnya bergetar. Apabila frekuensi natural sistem sama dengan frekuensi rangsangannya maka akan terjadi kondisi resonansi [11].

\section{Frekuensi natural}

Frekuensi natural atau frekuensi alami adalah sebuah sistem frekuensi yang 
bergetar akibat dari rangsangan impuls sesaat terhadap suatu eleman dari posisi kesetimbangannya [12]. Frekuensi natural terdapat pada seluruh benda yang memiliki kekauan dan massa. Besarnya frekuensi natural dapat diketahui dengan persamaan berikut.

$f_{n d} \approx f_{n}=\frac{1}{2 \pi} \sqrt{\frac{k}{m}}$

Frekuensi natural adalah frekuensi yang berpengaruh terhadap terjadinya resonansi. Frekuesi natural dengan frekuensi eksitasi tidak boleh memiliki nilai yang sama untuk menghindari terjadinya resonansi, sehingga nilai frekuensi natural perlu diketahui.

\section{Frekuensi eksitasi}

Frekuensi eksitasi adalah frekuensi yang dimiliki oleh penghasil gaya eksternal (eksitasi). Frekuensi eksitasi yang ditimbulakan dari baling-baling dan mesin induk dapat menjadi penyebab terjadinya resonansi pada struktur kapal.[13]

Besarnya frekuensi eksitasi yang terjadi akibat pengaruh mesin induk adalah sebagai berikut:

$$
f=\frac{2 \cdot \pi \cdot R P M}{60}
$$

dimana:

$\mathrm{RPM}=\mathrm{RPM}$ mesin induk

Angka 60 karena 1 menit $=60$ detik

\section{Resonansi}

Getaran yang berlebih dapat mengakibatkan masalah pada struktur kapal apabila kondisi resonansi terjadi. Resonansi terjadi saat frekuensi eksitasi dari mesin atau baling-baling bertemu atau memiliki nilai yang sama dengan salah satu frekuensi natural. Saat kondisi resonansi, besarnya amplitudo getaran hanya dibatasi oleh redaman sistem. Redaman yang terjadi pada struktur kapal umumnya bernilai sangat kecil sehingga nilai amplitudo pada kondisi resonansi secara relatif lebih besar apabila kondisi tersebut dibandingkan dengan kondisi tidak resonansi [12].

Dalam perhitungan getaran, harus dipertimbangkan eksitasi dan respon getarannya. Respon getaran memiliki persamaan sebagai berikut:

$$
X=\frac{F / k}{\sqrt{1-\left(\frac{f}{f n}\right)^{2}+2 \zeta\left(\frac{f}{f n}\right)^{2}}}
$$

Koefisien redaman $\zeta$ berasal dari redaman hidrodinamika dan redaman struktural pada posisi thrust block dan fondasinya. Redaman hidrodinamika umumnya lebih dominan jika dibandingkan dengan redaman struktural, akan tetapi harga $\zeta$ yang diambil secara kovensional yaitu $\zeta=0.05$.

\section{Standar getaran pada kapal}

Salah satu pasal dari peraturan ABS berbunyi sebagai berikut: "Getaran longitudinal sistem propulsi dianggap berlebihan apabila Root Mean Square $(R M S)$ amplitudo percepatannaya lebih besar dari $0.25 * \mathrm{~g}$ "[14]. Dalam banyak kasus amplitudo diasumsikan konstan sehingga

$$
\begin{gathered}
A_{R M S}=A \\
A_{R M S}=\left[\frac{R P M \cdot 2 \pi \cdot N}{60}\right]^{2} X \\
A_{R M S}<0,25 . g
\end{gathered}
$$

\section{Kebisingan}

Kebisingan di bawah air yang disebabkan oleh propeller terjadi disebabkan adanya kavitasi. Kebisingan yang terjadi langsung di transmisikan ke air. Kebisingan yang dihasilkan dari kapal-kapal besar seperti tanker bernilai $190 \mathrm{~dB}$ lebih, sedang kapal ukuran sedang menghasilkan sekitar 150-170 dB. ICES 209 secara efektif membentuk standar kebisingan melalui kapal ikan yang dijadikan kapal penelitian. Untuk itu perlunya analisis tingkat radiasi kebisingan yang dihasilkan sistem propulsi kapal yang bersumber dari propeller. Batas standar maksimum kebisingan kapal menurut ICES 209 yaitu $135 \mathrm{~dB}$ [15].

\section{Standar Kebisingan}

Dengan menggunakan Metode Miston (1995) tingkat radiasi kebisingan bisa di analisis sebagai berikut: 


$$
S L=135-1.66 \log 10\left[\frac{F H z}{1 H z}\right]
$$

dimana SL adalah tingkat sumber kebisingan dan $\mathrm{FHz}$ merupakan frekuensi natural.

Pemakaian persmaan diatas digunakan untuk frekuensi $1 \mathrm{~Hz}$ hingga $1 \mathrm{kHz}$. Untuk lengkapnya dapat dilihat dari gambar berikut.

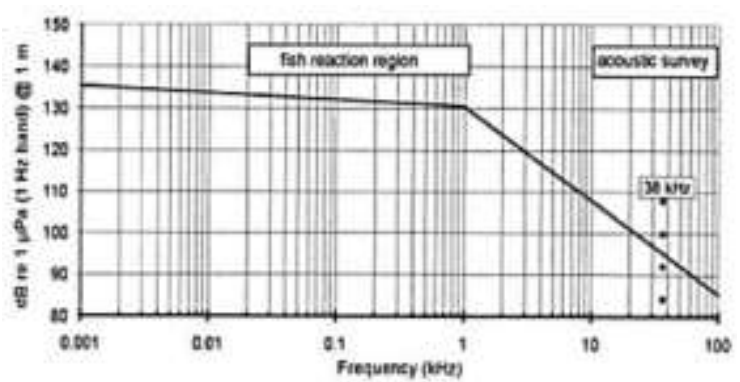

Gambar 1. Kurva Radiasi Kebisingan Menurut ICES

\section{Metode Penelitian}

Penelitian ini dilakukan dengan metode elemen hingga menggunakan bantuan FEA Software.

\section{Permodelan}

Dalam langkah ini, dilakukan pembuatan model elemen hingga dari kapal cepat aluminium. Dalam permodelan kapal digunakan gambar konstruksi profil dari tiap gading dan ukururan utama kapal sebagai berikut

\begin{tabular}{ccc}
\multicolumn{3}{l}{ Tabel 1 . Data Ukuran Utama Kapal } \\
\hline No & Data Kapal & Ukuran \\
\hline 1 & Length Overall & 41.60 meter \\
2 & Breadth & 6.95 meter \\
3 & Height & 2.90 meter \\
4 & Draught & 1.30 meter \\
5 & Main Engine & 3 x $1450 \mathrm{HP}$ \\
6 & $V s$ & $32 \mathrm{knot}$ \\
7 & $R P M$ & $2100 \mathrm{RPM}$
\end{tabular}

Berikut merupakan hasil permodelan kamar mesin kapal cepat aluminium pada frame 6 -frame 17.

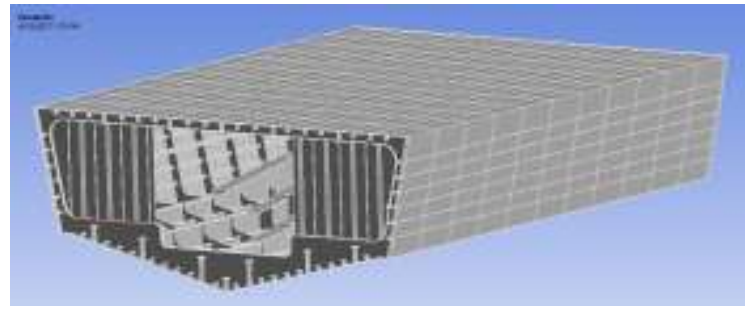

Gambar 2. Model Kamar Mesin

Dalam permodelan ini sumbu $\mathrm{x}$ menunjukkan panjang model, sumbu $\mathrm{y}$ menunjukkan lebar model, dan sumbu $\mathrm{x}$ menunjukkan tinggi model.

\section{Meshing}

Meshing merupakan suatu proses dalam analisis elemen hingga untuk membuat keseluruhan model terbagi menjadi beberapa elemen yang lebih kecil agar didapatkan hasil analisis yang detail pada model tersebut. Apabila meshing tidak sesuai maka model tidak dapat di run dan hasil analisis pun menjadi tidak valid.[4]

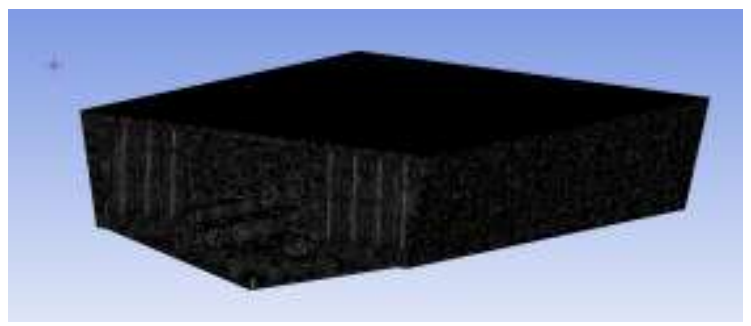

Gambar 3. Hasil Meshing Model

Jenis meshing yang digunakan pada model adalah coarse mesh dimana ukuran elemen yang digunakan relatif besar (tidak halus).

\section{Kondisi Batas}

Pemberian tumpuan atau kondisi batas diperlukan dalam melakukan analisis elemen hingga [16].

Mengacu pada (DNV-GL, 2015), disebutkan bahwa metode 3-2-1 Minimal Supports cocok digunakan untuk kondisi batas untuk kapal [17]. 


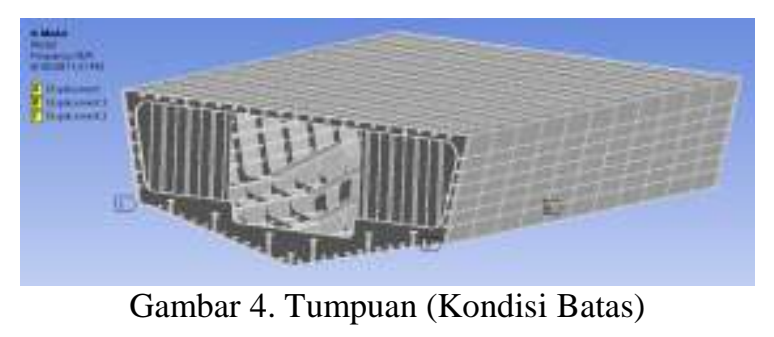

\section{Hasil dan Pembahasan}

Dalam analisis mode shapes atau ragam bentuk pada program analisis elemen hingga, solusi yang didapat berupa frekuensi natural.

Berdasarkan hasil running yang telah dilakukan, frekuensi natural dari model kamar mesin dan geladak didapatkan sebagai berikut. Pada analisis model ini, dicari 250 ragam bentuk dan frekuensi natural pertama. Berikut merupakan nilai frekuensi natural untuk setiap mode atau bentuk yang didapat dari hasil analisis FEA Software.

Tabel 2. Nilai frekuensi natural

\begin{tabular}{cccc}
\hline Mode & Fn $(\mathrm{Hz})$ & Mode & Fn $(\mathrm{Hz})$ \\
\hline 1 & 0.56 & 130 & 344.87 \\
10 & 47.87 & 140 & 359.88 \\
20 & 93.79 & 150 & 378.04 \\
30 & 124.27 & 160 & 402.85 \\
40 & 150.46 & 170 & 421.81 \\
50 & 172.82 & 180 & 440.34 \\
60 & 196.21 & 190 & 454.19 \\
70 & 219.35 & 200 & 470.85 \\
80 & 240.45 & 210 & 488.04 \\
90 & 264.23 & 220 & 503.64 \\
100 & 281.85 & 230 & 521.82 \\
110 & 301.43 & 240 & 536.85 \\
120 & 322.76 & 250 & 551.12 \\
\hline
\end{tabular}

Dari hasil data yang didapat, perlu diketahui RPM dari mesin induk yang digunakan pada kapal cepat aluminium ini adalah $2100 \mathrm{rpm}$ dalam kondisi kecepatan penuh. Sehingga frekuensi eksitasinya dapat dihitung sebagai berikut:

$$
f=\frac{2 \cdot \pi \cdot R P M}{60}
$$

$$
\begin{aligned}
f & =\frac{2 \cdot \pi \cdot 2100}{60} \\
& =220 \mathrm{rad} / \mathrm{s} \\
& =35.014 \mathrm{~Hz}
\end{aligned}
$$

Besarnya nilai amplitudo getaran pada sistem perlu diketahui terlebih dahulu sebelum mengetahui apakah akan timbul masalah dari besarnya getaran yang terjadi, kemudian nilai tersebut dibandingkan dengan standar yang ada, berikut hasil perhitungan amplitudo sistem yang didapatkan dari hasil perhitungan.

Tabel 3. Nilai Amplitudo Sistem

\begin{tabular}{ccc}
\hline Mode & $\begin{array}{c}\text { Frekuensi } \\
\text { Natural }(\mathrm{Hz})\end{array}$ & $\begin{array}{c}\text { Amplitudo } \\
\text { Sistem }(\mathrm{mm})\end{array}$ \\
\hline 1 & 0.56028 & $4.03 \times 10^{-7}$ \\
10 & 47.869 & $8.27 \times 10^{-7}$ \\
20 & 93.789 & $6.41 \times 10^{-7}$ \\
30 & 124.27 & $8.81 \times 10^{-7}$ \\
40 & 150.46 & $8.98 \times 10^{-7}$ \\
50 & 172.82 & $2.28 \times 10^{-6}$ \\
60 & 196.21 & $8.58 \times 10^{-7}$ \\
70 & 219.35 & $6.99 \times 10^{-7}$ \\
80 & 240.45 & $8.71 \times 10^{-7}$ \\
90 & 264.23 & $1.40 \times 10^{-6}$ \\
100 & 281.85 & $1.14 \times 10^{-6}$ \\
110 & 301.43 & $1.08 \times 10^{-6}$ \\
120 & 322.76 & $7.84 \times 10^{-7}$ \\
130 & 344.87 & $6.51 \times 10^{-7}$ \\
140 & 359.88 & $1.29 \times 10^{-6}$ \\
150 & 378.04 & $6.23 \times 10^{-7}$ \\
160 & 402.85 & $8.85 \times 10^{-7}$ \\
170 & 421.81 & $1.01 \times 10^{-6}$ \\
180 & 440.34 & $9.57 \times 10^{-7}$ \\
190 & 454.19 & $8.66 \times 10^{-7}$ \\
200 & 470.85 & $9.46 \times 10^{-7}$ \\
210 & 488.04 & $1.48 \times 10^{-6}$ \\
220 & 503.64 & $1.81 \times 10^{-6}$ \\
230 & 521.82 & $6.48 \times 10^{-7}$ \\
240 & 536.85 & $7.63 \times 10^{-7}$ \\
250 & 551.12 & $8.03 \times 10^{-7}$ \\
\hline & &
\end{tabular}

Setelah nilai amplitudo getaran pada sistem didapatkan, maka dapat diketahui standar kelayakan getarannya. 
Telah dilakukan perhitungan dan analisis standar getaran Arms terhadap seluruh 250 bentuk pertama mode shapes hasil analisis FEA Software dan didapatkan data nilai seperti yang terlihat pada Tabel dibawah dan membentuk kurva nilai frekuensi natural terhadap standar getaran pada Gambar dibawah sebagai berikut:

Tabel 4. Nilai Standar Getaran

\begin{tabular}{ccc}
\hline Mode & $\begin{array}{c}\text { Frekuensi } \\
\text { Natural }(\mathrm{Hz})\end{array}$ & $\begin{array}{c}\text { Standar } \\
\text { Getaran }\end{array}$ \\
\hline 1 & 0.56 & 0.312 \\
10 & 47.87 & 0.640 \\
20 & 93.79 & 0.496 \\
30 & 124.27 & 0.683 \\
40 & 150.46 & 0.695 \\
50 & 172.82 & 1.767 \\
60 & 196.21 & 0.665 \\
70 & 219.35 & 0.541 \\
80 & 240.45 & 0.674 \\
90 & 264.23 & 1.081 \\
100 & 281.85 & 0.883 \\
110 & 301.43 & 0.833 \\
120 & 322.76 & 0.607 \\
130 & 344.87 & 0.504 \\
140 & 359.88 & 1.001 \\
150 & 378.04 & 0.483 \\
160 & 402.85 & 0.685 \\
170 & 421.81 & 0.784 \\
180 & 440.34 & 0.741 \\
190 & 454.19 & 0.670 \\
200 & 470.85 & 0.733 \\
210 & 488.04 & 1.142 \\
220 & 503.64 & 1.404 \\
230 & 521.82 & 0.502 \\
240 & 536.85 & 0.591 \\
250 & 551.12 & 0.622 \\
\hline & &
\end{tabular}

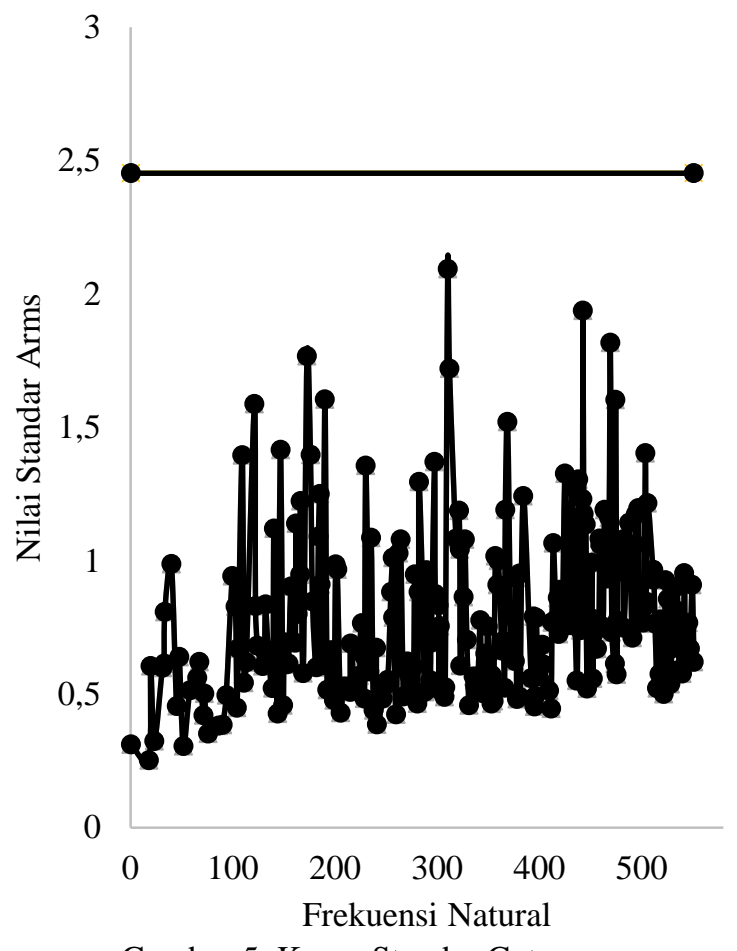

Gambar 5. Kurva Standar Getaran

Dari seluruh data hasil perhitungan yang didapatkan pada 250 bentuk dan nilai frekuensi natural pada konstruksi kamar mesin dan geladak nilai rata-rata Arms< $0.25 \mathrm{~g}$, yang dapat dinyatakan dalam kondisi aman.

Selain menaganalisis standar getaran, diperlukan juga diketahui tingkat kebisingan yang terjadi pada setiap mode yang telah dianalisis. Perhitungan tingkat radiasi kebisingan dilakukan menggunakan bantuan spreadsheet software.

Perhitungan ini merupakan metode estimasi yang berpatokan pada standar ICES 209 untuk menentukan nilai kebisingan pada kapal. Dikarenakan nilai frekuensi natural yang didapat dari 250 bentuk pertama hasil analisis FEA Software kurang dari 1kHZ, maka nilai dari tingkat radiasi kebisingan dapat diketahui sebagai berikut:

Tabel 5. Nilai Standar Kebisingan

\begin{tabular}{ccc}
\hline Mode & Fn $(\mathrm{Hz})$ & Standar Kebisingan \\
\hline 1 & 0.56 & 133.2605 \\
10 & 47.87 & 132.2111 \\
20 & 93.79 & 131.7262 \\
30 & 124.27 & 131.5234 \\
40 & 150.46 & 131.3855 \\
50 & 172.82 & 131.2856 \\
\hline
\end{tabular}




\begin{tabular}{ccc}
\hline 60 & 196.21 & 131.1941 \\
70 & 219.35 & 131.1137 \\
80 & 240.45 & 131.0475 \\
90 & 264.23 & 130.9795 \\
100 & 281.85 & 130.9330 \\
110 & 301.43 & 130.8846 \\
120 & 322.76 & 130.8353 \\
130 & 344.87 & 130.7875 \\
140 & 359.88 & 130.7568 \\
150 & 378.04 & 130.7213 \\
160 & 402.85 & 130.6755 \\
170 & 421.81 & 130.6423 \\
180 & 440.34 & 130.6113 \\
190 & 454.19 & 130.5890 \\
200 & 470.85 & 130.5630 \\
210 & 488.04 & 130.5372 \\
220 & 503.64 & 130.5145 \\
230 & 521.82 & 130.4889 \\
240 & 536.85 & 130.4684 \\
250 & 551.12 & 130.4495 \\
\hline
\end{tabular}

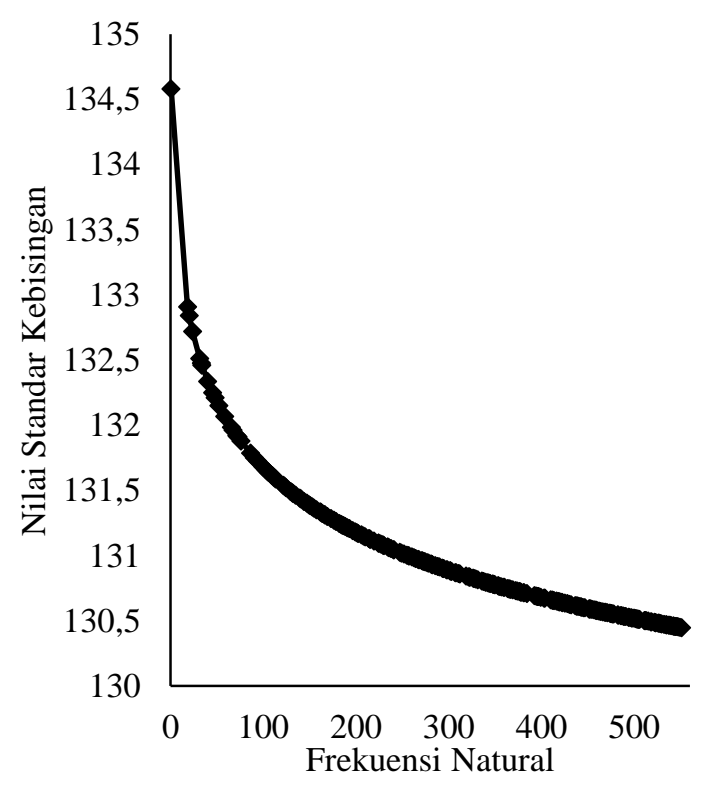

Gambar 6. Kurva Standar Kebisingan

Secara keseluruhan dari hasil perhitungan dari 250 mode didapatkan hasil nilai tingkat radiasi kebisingan berada dibawah standar sehingga dapat dinyatakan aman untuk tingkat kebisingannya.

\section{Kesimpulan}

Berdasarkan dari seluruh hasil analisis dan perhitungan yang dilakukan, dapat ditarik kesimpulan yaitu nilai amplitudo getaran sistem pada kamar mesin dan geladak penumpang kapal cepat aluminium yang didapatkan dari hasil perhitungan analisis 250 mode shapes didapatkan hasil yang bervariasi dengan rentang nilai $3.273 \times 10^{-7}$ hingga $2.703 \times 10^{-6}$. Kemudian nilai standar getaran yang didapatkan berada di rentang nilai 0.253 hingga 2.093. Oleh karena itu seluruh nilai getaran pada 250 mode shape memenuhi standar getaran. Nilai radiasi kebisingan pada kamar mesin dan geladak penumpang kapal cepat aluminium didapatkan hasil variasi tingkat kebisingan dengan rentang nilai $134.582 \mathrm{~dB}$ hingga $130.449 \mathrm{~dB}$. Dari hasil penelitian dapat diketahui semakin besarnya frekuensi natural, maka nilai radiasi kebisingannya semakin kecil, sehingga seluruh nilai memenuhi standar radiasi kebisingan.

\section{Ucapan Terima Kasih}

Penulis ingin berterima kasih kepada kedua semua pihak karena telah memberikan banyak dukungan kepada penulis baik secara moril maupun materil.

\section{Referensi}

[1] C. HUDA, "Analisis Laju Korosi Material Aluminium 5083 Sebagai Aplikasi Bahan Lambung Kapal," J. Pendidik. Tek. Mesin UNESA, vol. 6, no. 02, p. 251226, 2017.

[2] M. Sunardi, Listijorini, E, Sahroni, "Machine ; Jurnal Teknik Mesin Vol . 2 No . 2 , Juli 2016 ISSN : 25022040 Pengaruh jarak sel bukaan balok terhadap kekuatan material dan karakteristik getaran Sunardi , Erny Listijorini , Muhamad Sahroni JurusanTeknik Mesin Universitas Sultan Ageng Tirtay," Mach. Tek. Mesin, vol. 2, no. 2, pp. 6-10.

[3] R. A. Arisandhi, "analisa getaran pada kapal sar ( search and rescue ) dengan material hdpe ( high density polyethilene ) final project - me 141501 vibration analysis in sar ( 
search and rescue ) boat using hdpe ( high density polyethilene ) material Departement of Marine ," 2016.

[4] E. Avi, A. Laakso, J. Romanoff, H. Remes, and I. Lillemäe-Avi, "Coarse mesh finite element model for cruise ship global and local vibration analysis," Mar. Struct., vol. 79, no. December 2020, 2021.

[5] T. R. Lin, J. Pan, P. J. O'Shea, and C. K. Mechefske, "A study of vibration and vibration control of ship structures," Mar. Struct., vol. 22, no. 4, pp. 730-743, 2009.

[6] U. Budi, "Peranan Baling Baling pada Gerakan Kapal," Teknik, vol. 33, no. 2, pp. 106-111, 2012.

[7] M. Riesner and O. el Moctar, "A numerical method to compute global resonant vibrations of ships at forward speed in oblique waves," Appl. Ocean Res., vol. 108, no. June 2020, p. 102520, 2021.

[8] Z. W. Huang and Y. H. Tan, "Experimental Investigation on Active Longitudinal Vibration Suppression of the Thrust Bearing," J. Phys. Conf. Ser., vol. 1314, no. 1, pp. 0-6, 2019.

[9] K. M. Kumala, "Dhani Priatmoko Taufik Fajar Nugroho ST , MSc . Abstract," pp. 1-14.

[10] K. . Wilson, "Ship vibration," Mar. Eng. Nav. Archit., pp. 312-326, 1955.

[11] M. B. Rahmat, I. Sutrisno, Budianto, A. W. Budi Santosa, and F. Nofandi, "Vibration Analysis of Ship-RUV Structure in Operational Conditions," IOP Conf. Ser. Earth Environ. Sci., vol. 519, no. 1, 2020.

[12] E. V. Lewis, No Title, Second Edi. USA: Society of Naval Architects and Marine Engineers (SNAME), 1988.

[13] A. Alam, A. B. Mapangandro, Amalia Ika W, and M U Pawara, "Fatigue Life Analysis of Ramp Door Ferry Ro-Ro Gt 1500 Using Finite Element Method," Maj. Ilm. Pengkaj. Ind., vol. 15, no. 1, pp. 42-49, 2021.
[14] American Bureau of Shipping, "Guidance Notes on Noise and Vibration Control for Inhabited Spaces," Am. Bur. Shipp., no. September, 2017.

[15] R. B. Mitson, underwater noise of research vessels. Denmark: International Council for the Exploration of the Sea Palzgade 2 - 4, DK-126 1 Copenhagen K Denmark.

[16] L. P. Adnyani, M. A. M. Arsyad, and S. D. Nurcholik, "Analysis of Fatigue Life of Tugboat Towing Hook Construction Using Finite Element Method," Kapal J. Ilmu Pengetah. dan Teknol. Kelaut., vol. 17, no. 2, pp. 86-94, 2020.

[17] DNV GL, Finite element analysis. Norwegia: DNV GL AS, 2015. 